\title{
Industrie 4.0
}

Liebe Leserin, lieber Leser,

Produktentwicklungsprozesse werden immer komplexer. Ursachen hierfür sind technische Entwicklungen wie das autonome Fahren, die Elektrifizierung des Antriebsstrangs und vor allem die Vernetzung von Maschinen und Anlagen.

Der Titel dieses Sonderhefts lautet „Industrie 4.0“. Denn Automobilhersteller und Zulieferbetriebe stehen aktuell vor der Herausforderung, nicht nur Produktionsdaten aus verschiedenen Quellen und über die gesamte Wertschöpfungskette hinweg miteinander in Beziehung zu setzen. Auch Engineering und Produktion rücken immer stärker mit der jeweils zugeordneten IT zusammen. Auf diesem Weg werden schließlich unterschiedliche Fähigkeiten, Denk- und Vorgehensweisen zusammengeführt mit dem Potenzial, die Effizienz von Prozessen erheblich zu verbessern.

Forscher sprechen schon von Industrie 5.0 auf Basis selbstlernender Roboter, wenn sie eine menschenähnlich funktionierende Produktion meinen. Die Vision, die hinter der nächsten industriellen Revolution steht, vernetzt Mensch und Maschine in der Produktion und fordert maximal flexible Systeme.

Schon heute existieren intelligente Maschinen wie Cobots (Collaborative Robots) und Plattformen, die kaum noch unserer Vorstellung von einem Industrieroboter ähneln. Sie sind mobil, arbeiten direkt mit dem Menschen zusammen und sie beziehen ihr Wissen aus der Cloud.

Ihnen stehen also herausfordernde Zeiten bevor, die wir mit dem Fachmagazin ATZproduktion für Ingenieure aus Engineering und technischem Einkauf in der Automobilproduktion ab 2019 wieder regelmäßig begleiten werden.

Wir wünschen Ihnen eine anregende Lektüre.

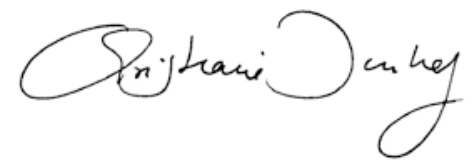

Christiane Imhof Redaktion ATZextra

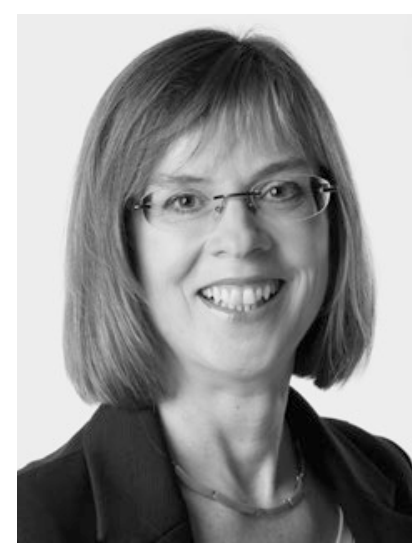

Pilz bietet alles, was Sie für die Automation Ihrer Maschinen und Anlagen brauchen: innovative Komponenten und Systeme, bei denen Sicherheit und Automation in Hardware und Software verschmelzen.

Automatisierungslösungen für die Sicherheit von Mensch, Maschine und Umwelt.

SPS IPC Drives

Halle 9, Stand 370 